\title{
THE DEVELOPMENT AND MANAGEMENT OF SMMES BY NEPAD
}

\author{
R Mears and DJ Theron, University of Johannesburg
}

\begin{abstract}
Purpose/objectives: The aim of this article is to demonstrate how NEPAD assists with the support and development of SMMEs in Africa. SMMEs can prove to be a major source of economic growth for African countries, but require much policy guidance as well as supporting resources.
\end{abstract}

Problem investigated: The concern about the NEPAD strategy is not its vision, but the uncertainty of its implementation and the lack of involvement or capacity of most of the role-players. The problem of capacity building in SMMEs is addressed in this article.

Design/Methodology/Approach: Drawing on research on NEPAD, SMMEs and related fields, the paper is mainly a literature review. It critically analyses the important role of NEPAD in the development of SMMEs in Africa. By drawing together the evidence on SMMEs, it generates a functional model for the strategic implementation of a plan to effect change through linkages or partnerships.

Findings/Implications: Most SMMEs in Africa are found in informal rural areas, which tend to be smaller, have lower growth rates and have a limited local market and skills base. Any initiative for implementing SMME strategies in Africa needs to be a bottom-up approach form a "grass roots" level. This paper presents a functional "grass roots" approach to capacity building through change agents.

Originality/Value: This article challenges the NEPAD strategy, which is a top-down approach. A microeconomic "grass roots" bottom-up approach to small and micro-enterprises is needed as well as financing to implement the model.

Conclusion: It is concluded that the prospects for effective implementation are dependent upon the appropriateness, feasibility and desirability of strategies. In this regard, a "grass roots" approach for capacity building in terms of training, support services and knowledge management is suggested.

Key Words: NEPAD (New Partnership for Africa's Development), SMMEs (Small, medium and micro-enterprises) partnerships, bottom-up approach, grass roots level.

\section{INTRODUCTION AND PURPOSE OF THIS PAPER}

The aim of this paper is to demonstrate how NEPAD assists with the support and development of SMMEs in Africa. SMMEs can prove to be a major source of economic growth for African countries, but require much policy guidance as well as supporting resources. The paper begins with a general exploration of SMME's and NEPAD before examining the support provided by and development challenges faced by NEPAD. The paper concludes with some implementation strategies proposed by NEPAD in its endeavours to improve African SMMEs.

\section{DESIGN/METHODOLOGYIAPPROACH}

This is mainly a literature review as the NEPAD has only been in operation for two years in its present form, making research evidence scarce. Sunde (2004) and Venter and Neuland (2005:446) state that 2005 marks the sixth year since the NEPAD process began as the Millennium Africa Recovery Plan (MAP), which is still a relatively short period. 


\section{SMMES AND THE HISTORICAL DEVELOPMENT OF NEPAD}

The medium-size component of SMMEs in Africa operates mainly in the formal manufacturing sector whereas the small and micro-enterprises are inclined to operate in the informal economic sector. According to Ronan (2005:5), the small- and micro sector can be regarded as a continuum, with small innovative entrepreneurs at the top end who respond to the pull of economic opportunities to expand their businesses, increase their incomes and eventually escape from poverty. At the bottom end are people engaged in some push economic activities that help them to survive, but are not able to bring them out of poverty.

According to Smallbone et al. (2002), most SMEs in Africa are found in informal rural areas that tend to be smaller, have lower growth rates and have a limited local market and skills base. The number of employees tends to be smaller (Cosh et al., 1996) and there are a large number with no employees at all (Centre for Rural Economy, 2000). The lack of large employers also has a 'knock-on' effect on smaller businesses (Countryside Agency, 1999). These SME's also tend to be less innovative and slower to adopt new technology (North, Smallbone \& Baldock, 1997). One of the keys to encouraging entrepreneurship in rural areas is considered to be innovation (Camagni, 1995). Another way to encourage SME's is to develop clusters and networks. Networks can provide levels of support and information that would not be available on their own. However, lower business densities tend to limit the scope for informal support networks (Cabinet Office, 1999). In such situations, the provision of public sector support to rural businesses becomes particularly important, with the constraints in rural areas making coordination of support delivery particularly important (Centre for Enterprise and Economic Development Research, 2002).

NEPAD can provide the overarching public policy required to guide, assist and provide structure for African SMMEs and has been developed from a number of previous African initiatives. South Africa's President Mbeki embarked on an African Renaissance during the late 1990's and gained the support of the Algerian and Nigerian presidents for the Millennium Africa Recovery Plan (MAP). The Omega Plan of Senegal's President Wade was developed in 2001 and focused on regional infrastructural development and the promotion of educational projects. On 3 July 2001, the MAP and Omega plans were merged to form the New Africa Initiative, which was approved by the OAU Heads of State. The initiative was renamed the New Partnership for Africa's Development (NEPAD) and was signed, finalised and launched in Abudja, Algeria on 23 October 2001 (De Waal, 2002:468).

As a long-term policy initiative of the African Union (AU), NEPAD provides the framework for the socio-economic upliftment of Africa for the next twenty years or more (Anon, 2004:1). The AU and NEPAD are both relatively new names on the African political landscape. They form part of a concerted drive by African leaders to put the continent on track towards growth, development and integration (Kotzé \& Steyn, 2003:39;11). Both the AU and the NEPAD strategies rely on the principle of increased African integration and unification, supported by African ownership and control. NEPAD furthermore seeks to coordinate efforts among African leaders and civil society to implement policies in a climate of joint responsibility and accountability. In short, NEPAD is an attempt by African leaders to collectively address the continent's lack of development in the context of globalisation (Gelb, 2002:1). The NEPAD (2001) policy document also refers to the need for capacity building in order to create implementation task forces. The NEPAD initiative is leadership-driven and loosely based on the assumption of a mandate from the African people. This is a top-down initiative in which the African people are neither recognised nor called on to give their views (Nabudere, 2004a and Venter \& Neuland, 2005:353).

Argo (2005) states that NEPAD may be used as a mechanism to realise and implement the vision of globalisation, by making it a reality for African nations and SMMEs in particular. Argo (2005) and Venter and Neuland (2005:433) state that small enterprises are recognised worldwide as the backbone of economies. Small businesses are a key source of jobs and the breeding ground for business ideas. 


\section{SUPPORT AND DEVELOPMENT OF SMMES BY NEPAD}

Developing SMMEs has been inhibited by systemic problems such as access to finance, technology, access to markets and the knowledge or ability to adapt to legal or policy changes. Moreover, micro and small individual entrepreneurs experience difficulties in achieving economies of scale for products due to high costs of equipment, raw materials finance and consulting services.

A mindset change of governments towards a more positive support for high growth sectors is needed and encouraged by NEPAD (Commission for Africa 2004:5). This includes improving the ability to graduate from the informal to the formal sector to bring the benefits to society as a whole. Large organisations have to adapt development policies for their supply chains, which treat this sector fairly and enable it to grow. Difficulties in registering businesses and unnecessary red tape that increase the cost of doing business have to be addressed. Globalisation has to create opportunities for all so that SMMEs, for example, can reach their full potential through NEPAD support.

Africa has yet to benefit from either globalisation or trade liberalisation. Its share of world trade is under two percent (UNCTAD, 2002 and UNCTAD, 2003a:2). Venter and Neuland (2004:273) state that increased market access is identified by NEPAD as a key prerequisite for African SMME development. NEPAD seeks to address the following three problems regarding market access. It firstly concentrates on African marginalisation in trade resulting from a lack of information on quality production standards and how to meet them. Secondly, the lack of policy coherence between macro and micro policies, mainly due to low government interest and support of SMMEs is addressed. This needs more and better-coordinated public-private sector dialogue. Thirdly, it focuses on underdeveloped human capital in terms of technical, financial and management skills that need to be developed with NEPAD support (UNCTAD, 2003a:39). These three problems contribute to the capacity gap that NEPAD aims to bridge in order to realise opportunities.

NEPAD identified the private sector as the engine of growth. It can realise trade and investment opportunities by promoting SMMEs in the manufacturing sector. The main objective is to increase production and product diversification in order to improve the competitiveness of the domestic private sector and by taking the following actions (UNCTAD, 2003a:39-40): Firstly, to promote a public-private sector dialogue so that national development strategies can be formulated. Secondly, it strengthens chambers of commerce and business associations and enhances the entrepreneurial and managerial capacities through support of technology acquisition and skills development. Lastly, NEPAD encourages the growth of SMMEs by the facilitation of access to capital.

A key pre-requisite in NEPAD's support of SMMEs is the development of a stable middle class with a stable business community of small exporters, craftsmen or manufacturers which can form a web of influence that causes the leadership to take care of their decisions (Schlemmer, 2004:15). Such a community becomes a check on power, and decisions become more responsible.

\section{DEVELOPMENT CHALLENGES OF SMMES FACED BY NEPAD}

While SMMEs are the backbone of the domestic economy, not many African governments have framed policies to enhance their growth and survival. Most African governments do not have a SMME act or even reliable statistics on SMMEs (NEPAD, 2001). NEPAD propagates the promotion of small entrepreneurs, given the fact that the African economies are largely driven by SMMEs (Anon, 2004:5).

Big businesses are in support of the culture and practice of Africans to take charge of their own destinations, while accepting the responsibilities, obligations, challenges and successes that accompany this development. Some 358 companies, parastatals, and business associations have signed the Business Endorsement of NEPAD by the end of July 2003 (Venter and Neuland, 2005:396). These 358 entities have acknowledged that mere cooperation is no longer regarded as an appropriate way to address underdevelopment, poverty and strife and have instituted mutually binding commitments or partnerships (Kotzé \& Steyn, 2003:113).

Respondents in the survey of African elites were asked to select the five biggest obstacles that could inhibit the development of the African continent from a list of twelve. Political instability was regarded 
as the most challenging issue facing the African continent. Four of the seven countries saw corruption as the most challenging issue, two political instability, and South Africa found HIVIAids most challenging. Poverty was placed in the top five issues of all countries surveyed, and a lack of accountable governments by five of the seven. HIVIAids was less important in relation to the other issues identified and gender inequality was not seen as an obstacle facing the African continent (Kotzé \& Steyn, 2003:7). While HIVIAIDS has received little attention within the NEPAD document (Kotzé \& Steyn, 2003:76-77), the impact of HIVIAids and poverty on the continent cannot be underestimated. According to Herbert (2002:15), NEPAD's blind spot is the social, economic and governance impact of HIVIAids.

Africans are furthermore becoming outsiders in a world of rapid technological change, new skills needs, and integrated production systems (UNCTAD, 2003b). The vast majority of African enterprises are also not ready for sustained networking and partnerships. The Tokyo Agenda for Action (TAA) is highly relevant to NEPAD market access goals and to put a select group of African entrepreneurs in shape to benefit from projects. However, Africa-Asia trade and investment opportunities have been blocked by many obstacles (UNCTAD, 2003a:40;44). Moreover, African entrepreneurs do not have the capital they need to make reliable partners for international entrepreneurs. Triangular partnerships between NEPAD, governments and the private sector are needed to share strategic information and strengthen the support and development of SMMEs (Anon, 2004:8).

Other negative factors for the continent as a whole include the high cost of regulation and labour market rigidity. The high cost of starting up a business has led to the growth of the informal business sector, which is essentially a survival mechanism. There is furthermore a low level of corporate governance and of foreign investment in Africa, despite the high profit margins. This is mainly attributable to too small markets and very little protection (Schlemmer, 2004:16).

Problems in Africa also stem from the neo-patrimonial policies introduced by African governments in an attempt to gain constituent support. This supports Kabemba's (2002:2) statement that Africa's problems are the result of misguided leadership, systematic corruption, economic mismanagement, senseless civil wars, political tyranny, flagrant violation of human rights, military vandalism, and bad policies.

Berry et al. (2002:38-39) raise a number of concerns regarding the effectiveness of SMME policy in South Africa. Among these are the general lack of awareness of the various services offered. Studies indicate that some 57 percent of emerging SMMEs in Gauteng and 70\% in the Western Cape are unaware of the support available to them. Services are also costly to entrepreneurs and service provision is also problematic as far as location and content are concerned. Most providers are located in the bigger magisterial districts, such as Johannesburg, so that outlying areas are relatively neglected. The authors consequently suggest that service providers promote their offerings more widely, that service delivery needs to be extended to outlying areas and that the degree of red tape in application processes needs to be reduced or streamlined.

\section{TOWARDS A “GRASS ROOTS” MANAGEMENT AGENDA}

The NEPAD's program of action is a holistic, comprehensive and integrated sustainable initiative for the revival of Africa. However, a couple of implementation issues must be addressed before the initiative can be of any real value in addressing SMME developmental issues. There is a clear realisation that economic growth through the planning and implementation of management strategies for capacity building and enhancing entrepreneurial capability is inextricably linked. However, the topdown approach as previously mentioned is leadership driven and seems to hamper the effective implementation of strategies at entrepreneurial levels. Nabudere (2004b quoted in Venter \& Neuland, 2005:92) states that a 'grass roots up' renaissance on a pan-African basis is needed rather than the 'top-down' agenda currently envisaged by most African leaders. The concern about the NEPAD strategy is not its vision, but the uncertainty of its implementation and the lack of involvement or capacity of most of the role players (Venter \& Neuland, 2005:358).

It is therefore imperative that an overarching initiative for implementing SMME strategies needs to be a bottom-up approach from "grass roots" levels. This approach could include the training of 
entrepreneurs and providing support services within an implementation framework as suggested below.

\section{The training of entrepreneurs}

The training of entrepreneurs in Africa has mostly been geared towards the needs of the formal sector. Training for SMMEs in the informal sector should include technical, social and business skills. Training should furthermore be demand-driven whereby people and groups ask for a particular type of training that they think will help them. Training for economic development, which is directed towards the top segment of small and micro enterprises in order to improve their products, increase their sales and ultimately provide employment for more people is needed. This can be done through the availability of Business Development Services (BDS) as proposed by the International Labour Organisation and elucidated by Ronan (2005:4). A symbiotic relationship between SMME clients and BDS providers are furthermore encouraged. The latter needs to provide needs-based information that can lead to significant skills transfer and enterprise growth. A similar approach by NEPAD (2001:Art 192) states that one of the best practices in promoting enterprises in highly innovative areas is through the establishment of business incubators. The incubators are established at the national level and draw on international experience and established best practice, while tailored to African needs and conditions (Venter \& Neuland, 2005:436). Entrepreneurship and small business development constitute the sine qua non for the success of the NEPAD strategy. Training for social development concerns vulnerable micro-enterprises that will not be able to grow to any significant size, due to weak purchasing power of potential customers. The key needs to be accessibility through free or inexpensive relevant training.

\section{Support services and knowledge management}

It is an accepted fact that training is not the panacea and that businesses require more than training to succeed. In this regard, Ronan (2005:8) suggests service centres be open to all clients and located at District Business Associations (DBAs). Such DBAs can provide appropriate tools and supervision as well as support services about markets and business operations. Knowledge management concerns information necessary for DBAs and BDSs to deliver programmes as well as the knowledge of entrepreneurs where they can sell their goods and/or services, possible new opportunities and general trends in the market. NEPAD can coordinate and assist here.

Adequate finance as another essential support service for SMME development has been identified as the most important factor determining the survival and growth of SMMEs. Commercial banks in general are reluctant to service SMMEs, because of the high transaction costs and risks, especially for micro-enterprises. Most African entrepreneurs simply do not have the capital they need to make reliable partners. Moreover, venture capital is not an option in most of Africa, because of the stringent market conditions required for venture capital (UNCTAD, 2003a:44). Central banks and designated financial service regulators must be proactive in developing a set of special measures for SMMEs. This can include guarantee programmes and more user-friendly and transparent disclosure systems to reduce the risks perceived by banks. In this regard, Zambia has witnessed a remarkable growth in micro-finance institutions (MFIs). However, according to Ronan (2005:7), most SMMEs are not utilising the services of the MFIs, either because of the high interest rates or just a lack of knowledge and/or information. Financial and fiscal incentives are also needed to support SMMEs with their cash flows or to assist disadvantaged enterprises in rural areas or distressed sectors (UNCTAD, 2003a:45). Financial incentives can include grants, subsidised credits and insurance at preferential rates. Fiscal incentives include tax holidays, reduction or exemption from taxes on profits, capital, labour, sales, value added, imports or exports. Other incentives such as subsidised infrastructure and utilities can also be used.

\section{An implementation framework}

No management strategy is viable if it does not include a well-articulated implementation framework, including a structure capable of implementing ideas to ensure that strategies, products and services are managed efficiently and effectively at operational levels. As the centralised entrepreneurial structure of SMMEs is typically built around the owner/manager with no division of responsibility, the 
founder may not have sufficient specialist knowledge in certain areas. This can prove to be a dilemma for some entrepreneurs, which could be overcome by developing supporting linkages together with an element of learning as the business develops. Linkages can be developed to accelerate the mobilisation of resources and promote their efficient use.

Figure 1 shows a functional model for the implementation of a strategic plan to effect change through linkages. This can be achieved in Africa with the support and management of NEPAD.

Figure 1: Functional model for strategic implementation in the SMME sector

\begin{tabular}{|l|l|l|l|l|}
\hline \multicolumn{1}{|c|}{ SMME SERVICES } \\
Training \\
Standards \\
Market intelligence \\
Micro-finance
\end{tabular}

\section{Source: Adapted from Ronan (2005:9)}

BDSs can be used to develop and enhance entrepreneurial capability by providing needs-based information and counselling and building symbiotic relationships between SMME clients and BDS providers. BDS furthermore needs to be available to SMMEs as a follow-up to training programmes. BDS can be delivered through orientation desk service centres for a limited clientele and trainees and can be located at DBAs. Micro-finance is seen, not least by governments, as an important part of the mix in supporting new and growing SMMEs in Africa. But hitherto, there has been little data to enable performance and value for money to be reviewed and compared. Nevertheless, MFIs and the lending products that they offer need to be communicated. Training on the advantages, the selection criteria and the use of credit should furthermore be conversed to SMME clients. Business incubators can draw on international experience while tailored to African needs and conditions. NEPAD has a proactive role to play in all these initiatives

\section{CONCLUSION AND IMPLICATIONS}

The NEPAD (2001) policy document refers to the need for capacity building in order to create implementation task forces. However, serious doubts remain about the current existence of adequate bureaucratic structures in many African countries to ensure the implementation of the idealistic plans, proposals and initiatives of the NEPAD strategy. Nevertheless, the promotion of small enterprises remains important, given the fact that Africa's economies are largely driven by SMMEs. The role of SMMEs is increasingly becoming central in the process of creating sustainable economic growth, poverty alleviation and socio-economic transformation. Entrepreneurship and the process of promoting SMMEs are of critical importance to further the NEPAD objectives for an African renaissance. The prospects for effective implementation are furthermore dependent upon the appropriateness, feasibility and desirability of strategies. In this regard, a "grass roots" approach for capacity building in terms of training, support services and knowledge management should be considered. A functional model for strategic implementation in the SMME sector through linkages and partnerships - as proposed in this paper - could accelerate the mobilisation of resources and their efficient use on the African continent. The attention paid to SMMEs by NEPAD will ultimately enable the African continent to start addressing the major issues of poverty and economic growth. It can also introduce a learning/partner environment that will pave the way for the effective implementation of future African business/economic initiatives.

\section{REFERENCES}

Anon. 2004. First NEPAD multi-stakeholders dialogue held in Sandton, South Africa on the 22-23 October 2004 [Online] Available from: http://www.iss.co.za/AF/RegOrg/nepad/stakehrep1.pdf 
Argo EF. 2005. Forging New Partnerships: NEPAD SMMEs and the Challenge of Globalization. Pretoria: Institute for Business Innovation.

Berry A, von Blotnitz R, Cassim R, Kesper A, Rajartnam B and van Sevenster D. 2002. The economics of SMMEs in South Africa. Johannesburg: Trade and Industrial Policy Strategists.

Cabinet Office. 1999. Rural Economies, a Performance and Innovation Unit Report. December. London: Cabinet Office.

Camagni RP. 1995. The Concept of Innovative Milieu and its Relevance for Public Policies in European Lagging Regions. Papers in Regional Science, 74(4):317-40.

Centre for Enterprise and Economic Development Research. 2002.Complementarity and Coordination of Support for the Self-Employed, Cheltenham: The Countryside Agency.

Centre for Rural Economy. 2000. Rural Microbusinesses in NE England: Final Survey Results, Newcastle: University of Newcastle Upon Tyne.

Commission for African. 2004. Statement from the Accra Business Round Table. Accra, Ghana. 1516 November 2004.

Cosh A, Duncan J and Hughes A. 1996. "Size, Age, Survival and Employment Growth", in Cosh, A. and Hughes, A. (eds), The Changing State of British Enterprise: Growth, Innovation and Competitive Advantage in Small and Medium Sized Firms 1986-95, ESRC Centre for Business Research, University of Cambridge.

Countryside Agency. 1999. The State of the Countryside 1999. Northampton: Countryside Agency.

De Waal A. 2002. What's New in the 'New Partnership for Africa's Development? International Affairs, 78(3):465-468.

Gelb S. 2002. NEPAD: Opportunities and challenges. In Gibbs, S. Hughes, T. Mills, G. \& Vaahtoranta, T. (eds). Charting a New Course: Globalization, African Recovery and the New Africa Initiative. Johannesburg: The South African Institute of International Affairs (SAllA).

Herbert R. 2002. Implementing NEPAD: A Critical Assessment. Johannesburg: SAIIA.

Kabemba C. 2002. The AU and NEPAD. Inside AISA 4, August 2002.

Kotzé H and Steyn C. 2003. African Elite Perspectives: AU and NEPAD; A Comparative Study Across Seven African Countries. Johannesburg: Konrad-Adenaue-Stiftung occasional papers.

Nabudere DW. 2004a. The Historical and Structural Impediments to the Implementation of the New Partnership for Africa's Development (NEPAD). Unpublished research paper: Uganda.

Nabudere DW. 2004b. NEPAD and the African Renaissance. Unpublished research paper. Pretoria: Institute for Business Innovation.

NEPAD. 2001. The New Partnership for Africa's Development. Pretoria: NEPAD Secretariat.

North D, Smallbone D and Baldock ER. 1997. Innovation and New Technology in Small Rural Firms. Rural Research Report No 33. Salisbury: Rural Development Commission.

Ronan N. 2005. Fostering Entrepreneurship in a Developing Country. Unpublished paper read at the Institute for Small Business \& Entrepreneurship 28th National Conference, Blackpool, UK, 1-3 November 2005. In digest of proceedings. 
Schlemmer L. 2004. Impediments and Possibilities of Socio-Economic Developments in Africa. Unpublished paper read at the SACOB Fifteenth Annual Convention, Caesars, Gauteng 3-5 October 2004. In digest of proceedings.

Smallbone D, North D, Baldock R and Ekanem I. 2002. Encouraging and Supporting Enterprise in Rural Areas. Small Business Service Research Report.

Sunde J. 2004. The Influence on and Involvement of Foreign Governments and International Institutions with NEPAD. Pretoria: Institute for Business Innovation.

Venter DJ and Neuland EW. 2004. The European Union and South Africa. Johannesburg: Richard Havenga \& Associates.

Venter DJ and Neuland EW. 2005. NEPAD and the African Renaissance. Johannesburg: Richard Havenga \& Associates.

UNCTAD. 2002. World Investment Report 2002: Transnational Corporations and Export Competitiveness. New York: United Nations publications. Sales no. E.02.II.D.4

UNCTAD. 2003a. Enhancing the Contribution of the Indigenous Private Sector to African Development: Opportunities for African-Asian Cooperation. A report prepared by the UNCTAD Secretariat for the UNDP/UNDESA Expert and High-level Meetings on TICAD. Morocco, April 2003.

UNCTAD. 2003b. Technology for Development: Investment and Technology Policies for Competitiveness. A report prepared by the UNCTAD Secretariat and Sanjaya Lall, New York: Oxford University: Forthcoming. 